\title{
A Conversation with Ling-Ling Chen
}

\author{
Interviewer: Steve MaO \\ Senior Editor, Science
}

\begin{abstract}
Ling-Ling Chen is a Professor of Shanghai Institute of Biochemistry and Cell Biology
\end{abstract} at the Chinese Academy of Sciences.

Steve Mao: Although you set up your independent laboratory less than 10 years ago, you've been studying RNA for a long time. In the last two decades, what do you think of the progress made in the RNA field?

Dr. Chen: We've had the wave of the noncoding RNA being discovered by so many different labs, from small RNAs to long noncoding RNAs [lncRNAs] to circular RNAs [circRNAs]. Those molecules are so fascinating. The discovery of so many of the noncoding RNAs has changed our view of how genes are regulated, how those noncoding RNAs can impact cells in many ways. We're lucky to work in RNA.

Steve Mao: People used to speculate those are junk portions because they do not code any proteins, but now it turns out that they actually code very important RNA species, and many of them play various roles. You started with IncRNA, and later you moved toward a precursor RNA that generates new lncRNAs ended with snoRNA [small nucleolar RNA]. Can you tell us what made you switch?

Dr. Chen: I wouldn't call it a switch, but really a smooth transition. Ten years ago, one of the most exciting discoveries in molecular biology was pervasive transcription of the genome, leading to the discovery of intergenic-regiontranscribed long noncoding RNAs [lincRNAs]. We know that the transcription and processing of long noncoding RNAs is different from those of mRNAs [messenger RNAs], but at the ends these mature lncRNAs look similar to mRNAs: They have $5^{\prime} \mathrm{m}^{7} \mathrm{G}$-capping or $3^{\prime}$ poly(A) tails with only a few exceptions, like NEAT1 [Nuclear Enriched Abundant Transcript 1] or MALAT1 [Metastasis-Associated Lung Adenocarcinoma Transcript 1], originally discovered by Dave Spector's lab right here at Cold Spring Harbor. His lab found that the 3'-end processing of these two basically used an RNase P cleavage related to tRNA [transfer RNA] biogenesis, and those RNAs look so different at the $3^{\prime}$ ends from mRNAs.

Luckily, I worked on NEAT1 with Gordon Carmichael at the time. Starting from those Alu elements, I found that mRNAs containing inverted Alu repeats are preferentially retained in the nuclei in bodies called paraspeckles.
I found that NEAT1 is a major organizer of paraspeckles. So, triggered by the very interesting, different appearance of NEAT1, I asked the question: Do all RNAs look the same as mRNAs? From there, I began to explore the nonpoly(A) transcriptome, which had been ignored by so many people as just junk. We discovered different classes of previously unknown species. These RNAs do not have their own promoters, but rather are processed from the primary Pol II [RNA Polymerase II] transcripts and then stabilized by distinct mechanisms like forming RNA circles, or by the protection of snoRNP [small nucleolar RNA-protein] complexes at one or both ends. More importantly, now we've figured out that some of them can impact important functions of gene regulation in cells that also relate to human diseases including Prader-Willi syndrome and autoimmune diseases like lupus. We're happy to see that these previously thought-of-as-junk things can do something in cells.

Steve Mao: I know that you studied immunology in a lupus setting, and you also studied the differentiation potential of human embryonic stem cells and the function of those RNAs. What's it like to transition from molecular biologist to all these different fields?

Dr. Chen: I was trained as an RNA biologist, so all the RNA stuff from my lab was rooted in molecular biology, but I just take every approach necessary to address the fundamental question I want to ask. For example, my lab routinely uses imaging as one way to look at how exactly a particular IncRNA localized in the cell. That can provide lots of information to predict what they do there. It happens that we found RNA circles because they are slowly generated and rapidly degraded. When they are there, they form these very interesting imperfect intramolecular double-stranded RNA [dsRNA] structures that act as inhibitors of PKR [protein kinase R] activation, which is a protein involved in innate immunity that is related to the autoimmune disease, lupus. For autoimmune diseases, we do collaborate. For example, we get our precious SLE [systemic lupus erythematosus] patient samples from a local collaborator, Dr. Nan Shen at Renji Hospital. For something like this, because I really don't know much of immunology, I tend to do collaborations with col-

(C) 2019 Chen. This article is distributed under the terms of the Creative Commons Attribution-NonCommercial License, which permits reuse and redistribution, except for commercial purposes, provided that the original author and source are credited. 
leagues. For other things, we try to do the most we can in the lab. As I said in the beginning, we try every approach necessary. The ultimate goal is to address what those mystery RNAs do in cells.

Steve Mao: This is a fascinating story: Linking a fundamental question from molecular biology - the role of the circular RNAs - with a very important disease-relevant role in innate immunity. A lot of these RNAs have been moving into the clinics. For example, SPINRAZA ${ }^{\circledR}$ - to treat SMA [spinal muscular atrophy] -is an antisense oligo to block splicing. You've mentioned that your work might provide a direction for therapy in the future to treat lupus patients. Can you elaborate how we can use circular RNA to advance into the clinics?

Dr. Chen: We were actually very excited to see this. Normally, these lupus patients have global reduction of circular RNA suppression accompanied with a burst of PKR activation. If we introduce RNA circles into blood cells that came from an SLE donor, we see reduced PKR activation together with this downstream cascade including interferon responses and interferon-induced genes, and many of those genes have been used as diagnostic markers of SLE. This really suggests that in the future we can introduce the in-vitro-synthesized circles without immunogenicity - in the beginning, with animal models - to see if the circles can reduce this unwanted PKR activation that could benefit patients in the future.

Steve Mao: You've described a very promising technology to try to study circular RNA in this meeting. Can you tell us something about that?

Dr. Chen: The biggest challenge in the circRNA field was that RNA circles have the structural conformation and they have almost the same sequences with the linear RNA that's basically from the same parental genes. The only difference is the backsplice at the junction site. So, because they came from the middle exons of the coding genes, it makes it very hard to interrupt the circular RNAs only without affecting the linear RNA expression with current existing CRISPR-Cas genome editing types of technology, as well as with RNAi because any half of RNAi is targeting the linear RNA.

A couple years ago, Feng Zhang's lab described the exciting CRISPR-Cas13 system. This system is proven to target RNA with high specificity. One of the very unique features of this system is that it is intolerant to mismatches that hybridize to the targeted RNA. I wanted to ask whether this technology could be used to only target and degrade circRNA without affecting linear expression. We did a panel screening and we found one of them worked well, and I'm sure maybe other Cas 13 proteins can also do the same thing: discriminate circRNAs from mRNAs.
Importantly, we also can manage the system to apply larger-scale functional circRNA screening. That means that with this new tool added to our existing tool kit we should be able to study circRNA function, not only at the individual level, but also at larger-scale levels in different biological settings. I'm really very excited. Hopefully, in the future we're going to see more individual circRNA functions discovered by different labs.

Steve Mao: A lot of your major discoveries come from this kind of non-hypothesis-driven genome-wide kind of discovery; you mentioned the poly $\left(\mathrm{A}^{-}\right)$portion. The challenge of doing this kind of data-driven research is that not every biologist is trained as a computational biologist, so you really need to have the kind of expertise to analyze the data. Can you say something about your experience collaborating with computer biologists?

Dr. Chen: I do both: genome-wide kind of discovery and hypothesis-driven discovery. Indeed, even for the genome-wide kind of discovery, I first had a hypothesis prior to performing the genome-wide studies. For example, we explored the poly $\left(\mathrm{A}^{-}\right)$portion with the hypothesis that some unknown but unconventionally processed RNAs might be missing from the classical poly $\left(\mathrm{A}^{+}\right)$portion. In terms of computational collaboration, I'm super lucky because my collaborator, Dr. [Li] Yang is the principal investigator at the CAS [Chinese Academy of Sciences] at the PICB [CAS-Max Planck Gesellschaft (MPG) Partner Institute for Computational Biology]. He also is my husband, so we have lots of discussions even when we're taking care of our daughter. My suggestion to do this kind of collaboration is to discuss with your collaborator as much as possible, because this way you can freely deliberate the key questions you want to address.

Steve Mao: There are really not a lot of female scientists, especially at the principal investigator [PI] level, in China. As a female scientist in this kind of male-dominant setting, what's the biggest challenge, and what things do you think could be done to improve that?

Dr. Chen: In my Institute, the Ph.D. students are at least $50 \%$ female and 50\% male, but at the PI level we have only $20 \%$ female, maximum. One of the reasons is that many female scientists grow discouraged by the apparent difficulties when they want to have a family. My advice for them: Don't be discouraged by the obvious apparent difficulties. Ask for help. Ask for support. Build up the support network with your families, with your friends, to get through the first several years when the kids are young, when they need a lot of intense attention. In the meantime, I always encourage female scientists: Just be self-motivated. Be self-confident and persistent. If you love science, give it passion. In this way, maybe 10 years later, you're not going to regret: "Oh, I gave up my science." 


\section{$\$_{\text {CSH\& }}^{\infty}$ Cold Spring Harbor Symposia SYMPOSIA on Quantitative Biology}

\section{A Conversation with Ling-Ling Chen}

Cold Spring Harb Symp Quant Biol published online December 20, 2019

Access the most recent version at doi:10.1101/sqb.2019.84.039032

$\mathbf{P}<\mathbf{P} \quad$ Published online December 20, 2019 in advance of the print journal.

Creative This article is distributed under the terms of the

Commons http://creativecommons.org/licenses/by-nc/4.0/, which permits reuse and

License redistribution, except for commercial purposes, provided that the original author and source are credited.

Email Alerting Receive free email alerts when new articles cite this article - sign up in Service the box at the top right corner of the article or click here.

Advance online articles have been peer reviewed and accepted for publication but have not yet appeared in the paper journal (edited, typeset versions may be posted when available prior to final publication). Advance online articles are citable and establish publication priority; they are indexed by PubMed from initial publication. Citations to Advance online articles must include the digital object identifier (DOIs) and date of initial publication.

To subscribe to Cold Spring Harbor Symposia on Quantitative Biology go to: http://symposium.cshlp.org/subscriptions 